\title{
EQUILIBRIUM IN THE SYSTEM: SILVER NITRATE AND PYRIDINE
}

\section{BY LOUIS KAHLENBERG AND ROBERT K. BREWER}

The fact that silver nitrate is soluble in pyridine has been known for some time. In 1886 Jörgensen ${ }^{1}$ prepared the two compounds $\mathrm{AgNO}_{3} \cdot 3 \mathrm{C}_{5} \mathrm{H}_{5} \mathrm{~N}$ and $\mathrm{AgNO}_{3} \cdot 2 \mathrm{C}_{5} \mathrm{H}_{5} \mathrm{~N}$ and tested their stability under the influence of heat. He also investigated the changes which these salts suffered when exposed to the air, and determined their solubility in different solvents. The molecular weight of silver nitrate in pyridine solution was investigated by means of the boiling-point method by Schmujlow, ${ }^{2}$ the electrical conductivity of such solutions was determined by Lincoln, ${ }^{3}$ and the difference of potential between such solutions and silver electrodes were measured by Kahlenberg. ${ }^{4}$ Aside from the work mentioned combinations of silver nitrate and pyridine have received no further attention.

It is the purpose of the present paper to present the results of investigations which have been made to determine the entire equilibrium curve in the system of silver nitrate and pyridine.

The pyridine was obtained from Merck and was dried over fused caustic potash until the sharpest edges of the latter were no longer affected. The product was then subjected to fractional distillation and the portion passing over between $115^{\circ}$ and i $16^{\circ} \mathrm{C}$ at $742 \mathrm{~mm}$ pressure was used in the future experiments. The silver nitrate was a very pure product. It was carefully fused in the dark to remove moisture. The salt was then finely pulverized. The saturated solutions of silver nitrate in pyridine were prepared in an apparatus similar to that used by Meyerhoffer and Saunders, ${ }^{5}$

\footnotetext{
${ }^{1} \mathrm{~J}$. prakt. Chem., 33, 50I (1886).

2 Zeit. anorg. Chem., I5, 23 (1897).

${ }^{3}$ Jour. Phys. Chem., 3, 469 (1899).

4 Ibid., 3, 386 (1899).

'Zeit phys. Chem., 28, 464 (I899).
} 
the glass screw stirrer being placed in a large hard glass test tube which was in turn immersed in a constant temperature bath. The temperature of the latter was carefully regulated. Below $0^{\circ} \mathrm{C}$ and down to the freezing-point of the saturated solution ice and salt, and finally solid carbon dioxide, were employed. Above $0^{\circ}$, up to $60^{\circ} \mathrm{C}$, a water bath was used, and from $60^{\circ}$ to $I 10^{\circ}$ a bath of molten paraffine served the purpose. Temperatures above $0^{\circ}$ were read on a thermometer graduated to tenths of a degree, while those below $0^{\circ}$ were read on a toluene thermometer graduated to one degree, which permitted estimations to tenths of a degree. These instruments were carefully calibrated by comparison with standard thermometers. Both the bath and the solution were constantly stirred by means of an efficient water motor. The mode of experimentation was simple in character. At intervals of $10^{\circ} \mathrm{C}$ or less the solvent was stirred with an excess of silver nitrate at constant temperature until equilibrium was secured. This required from one to three hours, the fact that the solution had become constant in composition being determined by analysis from time to time. In all cases samples of the solutions to be analyzed were taken by means of a pipette, the mouth of which was provided with a muslin cap which served as an efficient filter to hold back solid particles. These samples were run into a weighing bottle which was then securely stoppered and weighed. Each sample was then treated with dilute nitric acid in slight excess and the silver content determined by titration according to Volhard with a standard ammonium sulphocyanate solution using ferric alum as indicator. By separate experiment, it was established that the pyridine nitrate in these solutions in no way interfered with the estimation. When solutions of silver nitrate in pyridine are exposed for a long time to the light, they gradually darken. However, repeated determinations have shown that the amount of decomposition is too slight to affect the ordinary analytical results.

The experimental results are presented in the following table, which gives the number of grams of silver nitrate solu- 
ble in roo grams of pyridine. Each figure given is the mean of at least two determinations lying well within the limits of experimental error. As it is extremely difficult to keep solutions constant in temperature below $0^{\circ} \mathrm{C}$ and especially below $-20^{\circ} \mathrm{C}$, the results obtained at such temperatures are subject to a relatively larger experimental error. This difficulty was offset by making more determinations; and judging from the smoothness of the curve obtained, the figures secured are probably not far from the correct ones.

TABLE

Equilibrium between unsaturated solution and solid pyridine.

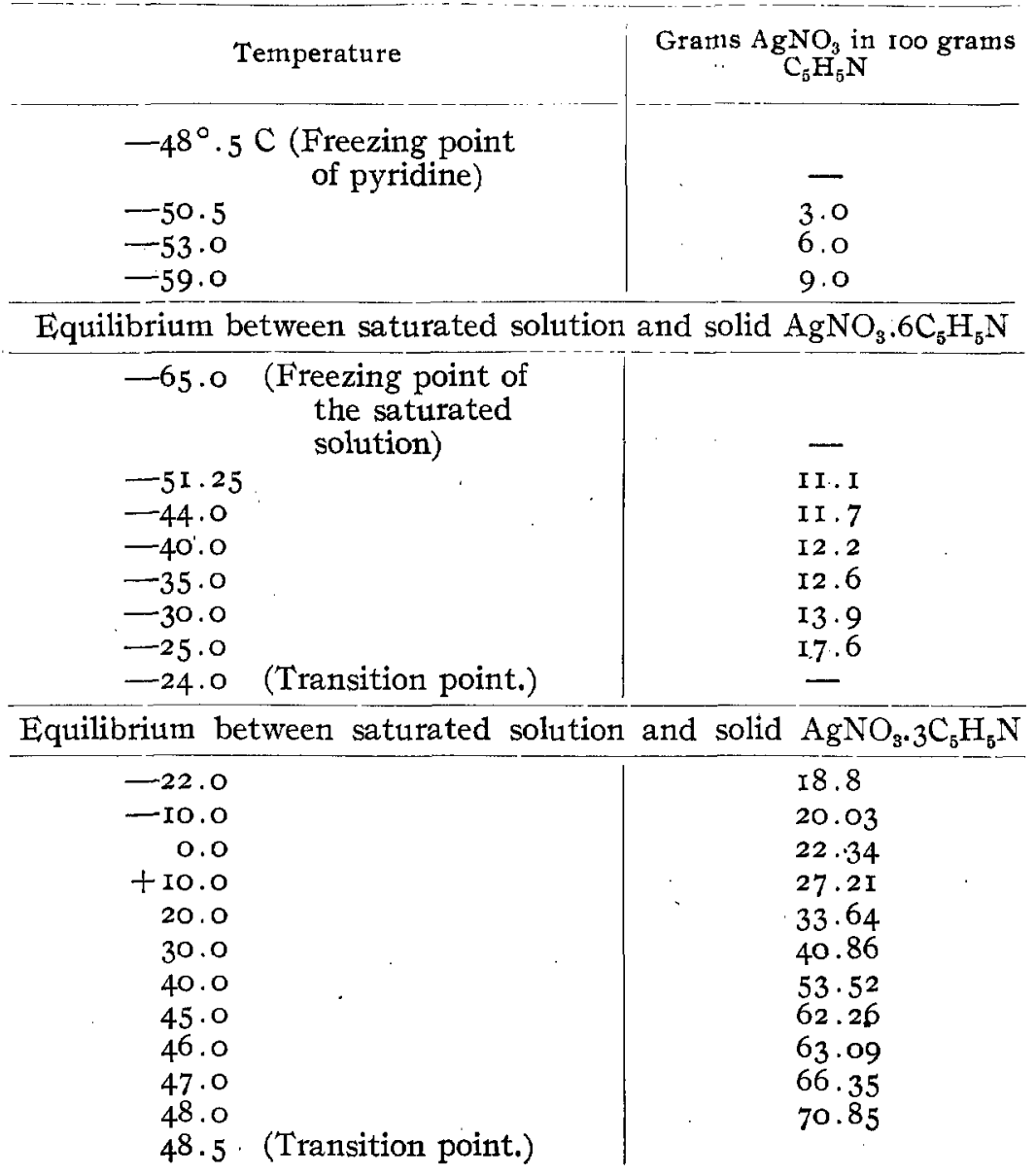


TABLE-(Continued),

Equilibrium between saturated solution and solid $\mathrm{AgNO}_{3} \cdot 2 \mathrm{C}_{5} \mathrm{H}_{5} \mathrm{~N}$

\begin{tabular}{c|c}
\hline \multicolumn{1}{c|}{ Temperature } & Grams $\mathrm{AgNO}_{3}$ in 100 grams \\
\hline 45.0 & 69.85 \\
50.0 & 72.25 \\
60.0 & 78.60 \\
70.0 & 89.10 \\
80.0 & $121.2 \mathrm{I}$ \\
$87.0 \quad$ (Indifferent point.) & 215.02 \\
80.0 & 228.5 \\
74.0 & 230.6 \\
\hline
\end{tabular}

Equilibrium between saturated solution and solid $\mathrm{AgNO}_{3}$.

\begin{tabular}{r|r}
74.0 & 225.4 \\
80.0 & 230.4 \\
87.0 & 237.1 \\
90.0 & 241.9 \\
100.0 & 253.8 \\
110.0 & 271.4
\end{tabular}

The results presented in the table are shown graphically in the accompanying figure, temperature being charted as abscissas and amounts of silver nitrate, in grams, soluble in roo grams of pyridine, being represented as ordinates.

The freezing point of the pure pyridine was found to be $-48.5^{\circ} \mathrm{C}$, and the curve between the latter temperature and $-65.0^{\circ}$ represents the equilibrium between solid pyridine and the unsaturated solution; in other words, this part of the curve is the so-called freezing point curve. At $-65^{\circ}$ $\mathrm{C}$ salt and solid pyridine separate out together and on lowering the temperature further the whole mass congeals. At $-65^{\circ}$ we have then a quadruple point at which the four phases, solid pyridine, solid salt, saturated solution and vapor are in equilibrium with one another. The solubility gradually increases from $-65^{\circ}$ to $-24^{\circ}$ as is shown by the curve. The solid which is in equilibrium with the saturated solution between these temperatures has the composition $\mathrm{AgNO}_{3} \cdot 6 \mathrm{C}_{5} \mathrm{H}_{5} \mathrm{~N}$. The crystals of this compound were minute 
and so unstable above $-25^{\circ} \mathrm{C}$ that an attempt to establish their crystal form was not made. The analysis yielded 25.0 percent $\mathrm{AgNO}_{3}$, whereas the compound $\mathrm{AgNO}_{3} .6 \mathrm{C}_{5} \mathrm{H}_{5} \mathrm{~N}$ would have a content of 26.3 percent $\mathrm{AgNO}_{3}$. The some-

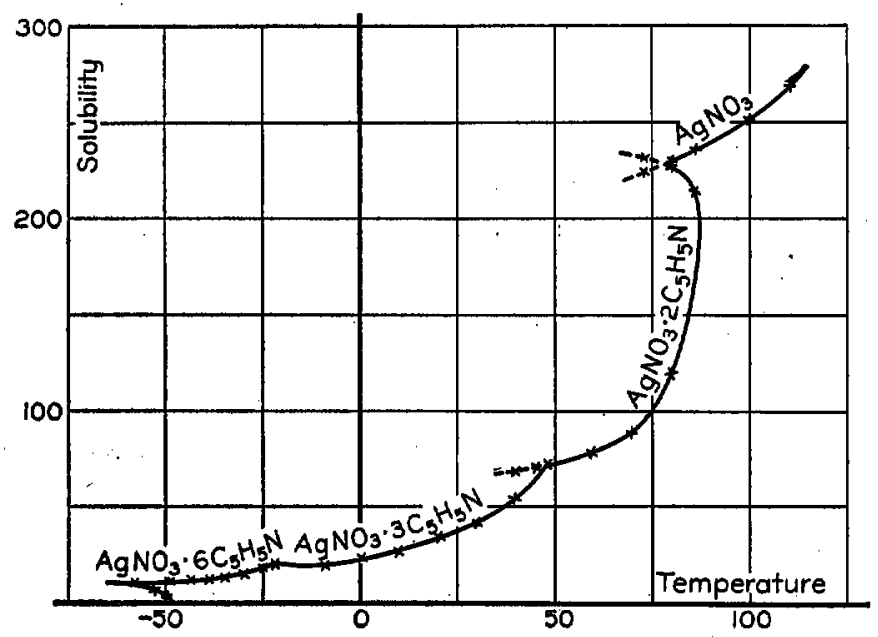

what low result is readily accounted for by the fact that it is practically impossible to free the crystals completely from adhering mother liquor. Hitherto the compound $\mathrm{AgNO}_{3}$. $6 \mathrm{C}_{5} \mathrm{H}_{5} \mathrm{~N}$ has been unknown.

From $-24^{\circ}$ to $+48.5^{\circ}$ the solubility curve changes its trend. The solid which is in equilibrium with the solution has a composition corresponding to the formula $\mathrm{AgNO}_{3} \cdot{ }_{3} \mathrm{C}_{5} \mathrm{H}_{5} \mathrm{~N}$. By analysis the crystals were found to contain 4 I.8 percent $\mathrm{AgNO}_{3}$, whereas the formula $\mathrm{AgNO}_{3} \cdot{ }_{3} \mathrm{C}_{5} \mathrm{H}_{5} \mathrm{~N}$ requires. 4I.6 percent $\mathrm{AgNO}_{3}$. At $24^{\circ}$ we have therefore another quadruple point at which there is equilibrium between the phases, vapor, saturated solution, and the two solids $\mathrm{AgNO}_{3} \cdot 6 \mathrm{C}_{5} \mathrm{H}_{5} \mathrm{~N}$ and $\mathrm{AgNO}_{3} \cdot{ }_{3} \mathrm{C}_{5} \mathrm{H}_{5} \mathrm{~N}$. The latter compound may readily be obtained in form of large, apparently rhombohedral crystals which may be freed from mother liquor by quickly pressing them repeatedly between filter paper.

From $48.5^{\circ}$ upward the solubility increases rapidly with the temperature until $87^{\circ}$ is reached, at which point 
the solid in equilibrium with the saturated solution melts and the whole mass assumes a spongy consistency. Further addition of silver nitrate causes a lowering of the temperature of equilibrium until $79^{\circ} \mathrm{C}$ is reached. From $48.5^{\circ}$ up to $79^{\circ}$ the solid in equilibrium with the saturated solution is $\mathrm{AgNO}_{3} \cdot 2 \mathrm{C}_{5} \mathrm{H}_{5} \mathrm{~N}$. The crystals, which were obtained in the form of long needles, were freed from adhering mother liquor as much as possible and were found to contain 50.8 percent $\mathrm{AgNO}_{3}$, whereas the formula $\mathrm{AgNO}_{3} \cdot{ }_{2} \mathrm{C}_{6} \mathrm{H}_{5} \mathrm{~N}$ requires $5 \mathrm{I} .87$ percent $\mathrm{AgNO}_{3}$. The somewhat low result obtained is easily explained by the fact that it is well nigh impossible to remove the syrupy mother liquor completely from the crystals. At $48.5^{\circ}$ then we have another quadruple point at which the phases, vapor, saturated solution and the solids $\mathrm{AgNO}_{3}$. ${ }_{3} \mathrm{C}_{5} \mathrm{H}_{5} \mathrm{~N}$ and $\mathrm{AgNO}_{3}, 2 \mathrm{C}_{5} \mathrm{H}_{5} \mathrm{~N}$ are in equilibrium with one another.

When the temperature is raised above $79^{\circ}$, after having thus passed the melting-point of the compound $\mathrm{AgNO}_{3}$. ${ }_{2} \mathrm{C}_{5} \mathrm{H}_{5} \mathrm{~N}$ as described, the solid phase in equilibrium with the saturated solution again changes, in this case to $\mathrm{AgNO}_{3}$. Thus $79^{\circ}$ is another transition point. The portion of the curve from $79^{\circ}$ upward was followed to $\mathrm{IIO}^{\circ}$; above which point the vapor pressure of the pyridine becomes so great as to prevent sufficiently accurate determinations under ordinary pressures.

Some of the solid phases changed from one composition to another sufficiently slowly to make it possible to prolong a number of the curves into meta-stable regions. Thus upon cooling the solution in equilibrium with $\mathrm{AgNO}_{3} \cdot 2 \mathrm{C}_{5} \mathrm{H}_{5} \mathrm{~N}$ below the transition point $48.5^{\circ}$ a smooth curve was obtained to $45^{\circ}, i$. e. $3.5^{\circ}$ below the transition point. Below $45^{\circ}$ the solid soon changed over to $\mathrm{AgNO}_{3} \cdot 3 \mathrm{C}_{5} \mathrm{H}_{5} \mathrm{~N}$, showing that a state of meta-stable equilibrium had been entered after cooling below the transition point. The upper end of this part of the curve could also be prolonged beyond the transition point, $79^{\circ}$, to $74^{\circ}$, thus entering another region of metastable equilibrium. Again, on carefully cooling the saturated 
solution which was in equilibrium with $\mathrm{AgNO}_{3}$ (upper end of the entire curve) the solubility curve was prolonged downward through the transition point, $79^{\circ}$, to $74^{\circ}$, showing another case of meta-stable equilibrium. At temperatures below the last mentioned, the solution became more and more visçous, showing that the transition point had been passed.

Thus at any temperature between $74^{\circ}$ and $87^{\circ}$ three different solubilities of silver nitrate in pyridine are possible, depending upon the direction of approach to the given point. The very great increase in the solubility between $60^{\circ}$ and $\mathrm{I} \mathrm{IO}^{\circ}$ as compared with that between $-60^{\circ}$ and $50^{\circ}$ is especially noteworthy, nor ought one to lose sight of the fact that there is a very material disengagement of heat when pyridine and silver nitrate combine with each other.

\section{Summary}

It has, been shown in this paper that pyridine and silver nitrate form three well defined crystalline compounds with each other. The exact temperature limits within which these compounds can exist in stable equilibrium with the saturated solution have been determined. One of these compounds, namely, $\mathrm{AgNO}_{3} \cdot 6 \mathrm{C}_{5} \mathrm{H}_{5} \mathrm{~N}$, has not been isolated hitherto, while $\mathrm{AgNO}_{3} \cdot 3 \mathrm{C}_{5} \mathrm{H}_{5} \mathrm{~N}$ and $\mathrm{AgNO}_{3} \cdot 2 \mathrm{C}_{5} \mathrm{H}_{5} \mathrm{~N}$ have been known. The latter compound melts without decomposition at $87^{\circ}$, whereas the other two lose pyridine upon heating them in an attempt to melt them under atmospheric pressure. The freezing point of pure pyridine has been found to be $-48.5^{\circ}$, and the entire equilibrium curve in the system silver nitrate, pyridine, has been established from the freezing point of pyridine up to $\mathrm{IIO}^{\circ} \mathrm{C}$.

Laboratory of Physical Chemistry,

University of Wisconsin, Madison, January, I908. 